\title{
Might Heterostyly Underlie Spider Occurrence on Inflorescences? A Case Study of Palicourea rigida (Rubiaceae), a Common Shrub from Brazilian Cerrado
}

\author{
Suzana Diniz, ${ }^{1}$ Everton Tizo-Pedroso, ${ }^{2}$ Denise Lange, ${ }^{3}$ \\ Andréa Andrade Vilela, ${ }^{3}$ Danielle G. Justino, ${ }^{3}$ Fernanda Alves Martins, ${ }^{3}$ \\ Erika Germanos, ${ }^{4}$ Rafael Arruda, ${ }^{5}$ and Vanessa Stefani ${ }^{3}$ \\ ${ }^{1}$ Programa de Pós-Graduação em Ecologia, Instituto de Biologia, UNICAMP, Caixa Postal 6109, 13083-970 Campinas, SP, Brazil \\ ${ }^{2}$ Unidade Universitária de Morrinhos, Universidade Estadual de Goiás, 75650-000 Morrinhos, GO, Brazil \\ ${ }^{3}$ Laboratório de Ecologia ComportamentaL e de Interações_LECI, Instituto de Biologia, Universidade Federal de Uberlândia, \\ CP 593, 38400-902 Uberlândia, MG, Brazil \\ ${ }^{4}$ UNICEUB/FACES, 70790-075, Brasília, DF, Brazil \\ ${ }^{5}$ Instituto de Ciências Naturais, Humanas e Sociais, Universidade Federal de Mato Grosso, Campus Universitário de Sinop, \\ 78557-267 Sinop, MT, Brazil
}

Correspondence should be addressed to Vanessa Stefani, vastefani@hotmail.com

Received 3 August 2012; Revised 15 October 2012; Accepted 16 October 2012

Academic Editor: Kleber Del-Claro

Copyright ( 2012 Suzana Diniz et al. This is an open access article distributed under the Creative Commons Attribution License, which permits unrestricted use, distribution, and reproduction in any medium, provided the original work is properly cited.

\begin{abstract}
We carried out a research on the Palicourea rigida (Rubiaceae) inflorescences, a distylous shrub of Brazilian Cerrado. Our objective was to compare the inflorescence architectural complexity and its quality in the two floral morphs and search for any relationship with spider occurrence. In order to assess the quality of inflorescence resources, we quantified the nectar volume and its sugar concentration and the number of fruits and flowers (intact and aborted) for both inflorescence morphs with and without spiders. For the architectural heterogeneity, we quantified floral structures and inflorescence levels of branching. Spider occurrence was higher in longistylous inflorescences than in brevistylous ones. The sampled spiders were classified into the guilds ambushers, jumpers, or orb-weavers. Ambushers, jumpers, and total richness were much higher among longistylous inflorescences. We found no difference between morphs neither in volume or nectar concentration nor in amount of fruits and flowers. However, longistylous inflorescences presented greater architectural heterogeneity than brevistylous ones. Therefore, we suggested that architectural heterogeneity is an important factor underlying the occurrence of cursorial spiders on $P$. rigida inflorescences, which possibly arose from the relationship between refuge availability and inflorescence architecture.
\end{abstract}

\section{Introduction}

Spiders occur in almost all land environments, but more abundantly in vegetation-rich areas [1]. They frequently use plants as substrate to forage and represent one of the main predators that control phytophagous arthropods in natural and agricultural systems [2, 3]. Furthermore, spiders also represent a key-assemblage to plants, since they play a potentially critical role over the dynamics of local trophic networks $[4,5]$. Consequently, basic knowledge of what regulates spider richness and abundance is crucial to understand the dynamics of the arthropod community on plants.

Spiders can select substrate based largely on cues from host plant architecture, which may influence the spider assemblage distribution $[4,6,7]$. It has been shown, for example, that spider richness and abundance may be influenced by the density of branches [8], leaves [7], and spines [4] by the leaf morphology [9] and by the availability of plant structures distributed vertically $[10,11]$. Although the patterns between spider diversity and plant architectural complexity have been frequently demonstrated (e.g., $[4,6,7$, 
12]), the causal mechanism which determines these patterns has yet to be identified, and different physical [13] and biotical [5] components of the habitat should be involved. Among the possible causal mechanisms pointed out by the literature are refuge against intraguild predation, increases of prey abundance, refuge against physical disturbances, and providing of milder microclimatic conditions [13].

Inflorescences are more propitious to colonization by spiders once they present high prey abundance, favourable microclimate conditions, and refuge availability against predation $[14,15]$. However, the habitat patch choice by spiders can be influenced not only by the reproductive branch architecture, but also by the flower or inflorescence quality, such as nectar production and flower senescence state [16]. Since some flowers could be more or less attractive to spiders establishment and, therefore, present a more or less diverse spider assemblage, it would be possible that this differential spider distribution leads to variations of phytophagous impact on floral structures or seeds and, consequently, in reproductive success. For instance, [3] it was experimentally demonstrated that the spiders on or at least near inflorescences can influence herbivory rate, as well as visits by pollinators, which, by the way, leads to straight consequences for the plant adaptive value.

The species Palicourea rigida H.B.K. (Rubiaceae) is a common shrub (0.5-1.5 m tall) from Cerrado, a Brazilian savannah-like system, with a simple vegetative structure (1-2 stems and few large leaves). However, this plant species presents a very variable architecture regarding its reproductive branches, since inflorescences can have 1 up to 6 branching orders as well as from few up to hundreds of flowers. Even after the fall of the corolla, the nectaries still remain active in plants, as for other Rubiaceae species [17]. The plant of the P. rigida can be allocated to two distinct morphs (i.e., distyly): brevistylous or longistylous (Figure 1). The heterostyly in $P$. rigida may be distinguished through inflorescence architectural complexity and quality. So, the objectives of this study were (1) to compare the architectural complexity and spider occurrence between the two morphs of $P$. rigida; (2) to compare the inflorescence quality, which in this study we took as the nectar volume and sugar concentration, and as the number of fruits and flowers, intact and aborted, in the two morphs of P. rigida and in the presence and absence of spiders. Therefore, we used the $P$. rigida shrubs as a case study to test the following hypotheses: (1) spider richness would be higher on the morph with the highest architectural complexity; (2) the habitat (i.e., inflorescence) quality differ between brevistylous and longistylous morphs; (3) higher habitat quality, such as greater volume and sugar concentration, larger numbers of fruits and intact flowers, and lower number of aborted flowers, is positively correlated to the presence of spiders on brevistylous and longistylous inflorescences.

\section{Materials and Methods}

2.1. Area of Study. The study was conducted in Caldas Novas Mountain State Park (PESCAN), in south-eastern of Goiás

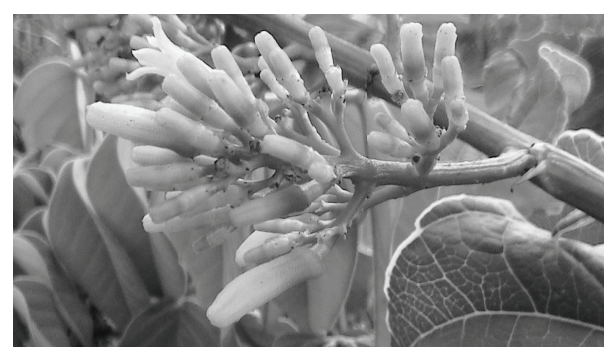

(a)

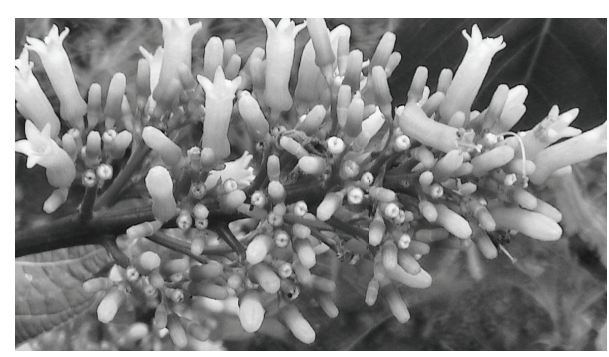

(b)

Figure 1: The $P$. rigida inflorescences: (a) brevistylous morph and (b) longistylous morph. Note the difference between the two morphs with regard to the architectural complexity.

state, at Brazil midwest $\left(17^{\circ} 43^{\prime} 56^{\prime \prime} \mathrm{S}\right.$ to $17^{\circ} 50^{\prime} 55.7^{\prime \prime} \mathrm{S}$ and $48^{\circ} 40^{\prime} 0^{\prime \prime} \mathrm{W}$ to $\left.48^{\circ} 42^{\prime} 57.6^{\prime \prime} \mathrm{W}\right)$. The Park has 12,500 ha, where Cerrado, tropical savanna-like vegetation, is predominant. The climate in the region has two well-defined seasons: dry from May to September and wet throughout the months of November, December, and January [18].

2.2. Studied Plant Species. The shrub Palicourea rigida H.B.K. (Rubiaceae) has its flowering season from September to March and fructifies from November to April. Additionally, P. rigida is the most common Palicourea species of the Brazilian Cerrado [19-21]. This species presents heterostyly of the distylous type (i.e., brevistylous and longistylous) (Figure 1), with the size and shape of stigmas and anthers differing between both of morphological types [22]. Heterostylous plants usually possess a self-incompatibility system, where fruit set occurs only after cross-pollination between morphs (legitimate cross-pollination) [21]. The species is pollinated by hummingbirds [22].

2.3. Spider Sampling. In the middle of the flowering season of 2008 in an area of $15,000 \mathrm{~m}^{2}$, we marked all the 36 shrubs of $P$. rigida with reproductive branches and with open flowers at a transect of $200 \mathrm{~m}$ long and $75 \mathrm{~m}$ wide using a global positioning device. As for each individual dealt with, we inspected, classified, and labelled the reproductive branches according to morphs of flowered inflorescence. Summing up, we observed whether they belonged to brevistylous or longistylous types. From the 36 plants, 15 were brevistylous and 21 were longistylous. We randomly selected one inflorescence from each of these 36 shrubs and collected manually the spiders on them. The spiders sampled were identified 
to the species level or assigned to a morphospecies. We also assigned the different spiders species or morphospecies sampled on $P$. rigida inflorescences to three different guilds: (1) ambushers, which included spiders thatdo not build snare webs for capturing prey and forage by sit-and-wait strategy-in this study, this guild was only composed by the family Thomisidae; (2) jumpers, which comprised spiders that do not build snare webs for capturing prey and hunt actively, often by jumping on their prey-the guild was composed by the families Salticidae and Oxyopidae; (3) orbweavers which included spiders that build snare orb-webs for capturing prey-the guild was composed only by the family Araneidae. In this study, we referred to the nonweb-building guilds of jumpers and ambushers as cursorial spiders.

2.4. Architectural Heterogeneity. Firstly, we measured the architectural heterogeneity through quantifying the number of primary, secondary, tertiary, quaternary, quinary, and senary branches, if they occurred. also, we quantified the number of different structures (such as closed and open buds, floral abortions, and infrutescences) presented in the distal part of each inflorescence and measured inflorescence length. For these measures, we sampled two inflorescences from eight shrubs of each morph. Finally, we divided, for each inflorescence sampled, the branch quantity from each branching level and the number of structures by their respective inflorescence length standardization of the architectural heterogeneity measures for inflorescences of different sizes. Furthermore, we also took note about spider presence or absence on the sampled inflorescences.

2.5. Sugar Concentration and Nectar Volume Produced. We used glass graduated micropipettes $(20 \mu \mathrm{L})$ for extracting and measuring the volume of nectar, whereas for measuring sugar concentration, we used the handheld refractometer ITREF90. For nectar and sugar measures, we sampled flowers from six randomly chosen brevistylous plants and five longistylous ones. From each plant, we sampled randomly two inflorescence and used, according to the availability of open flowers, $4.42 \pm 0.38$ (mean $\pm \mathrm{SE}$ ) flowers per inflorescence for brevistylous plants and $4.3 \pm 0.47$ for longistylous ones. We bagged the inflorescences with organza one day before the measurement in order to avoid contact with floral visitants. As nectar is produced continuously throughout the day, the volume and concentration measures were standardised for the same period of the day, between nine and eleven o'clock in the morning. We also took note whether the sampled inflorescence had spider on it or not.

2.6. Abundance of Fruits and Flowers. In plants where spiders occurred in some of their inflorescences, we randomly selected, from the same shrub, two inflorescence, with similar size and architecture, but one with spiders and another without. In both of these inflorescences, we quantified the number of intact and aborted flowers as well as the growing fruit. A total of 5 brevistylous and 15 longistylous plants were utilized. This difference in sampling size between the two morphs was unavoidable, since brevistylous inflorescences with spiders associated were far more scarce than longistylous ones.

2.7. Data Analysis. In order to compare the spider guild richness per inflorescence and the proportion of shrubs with spiders between brevistylous and longistylous morphs, we run the nonparametric bilateral Mann-Whitney $U$-test and $\chi^{2}$ test, respectively. The number of spider species associated with the two $P$. rigida morphs was estimated by Coleman rarefaction curve. We tested whether the nectar volume and sugar concentration differed between the two morphs and between inflorescences with and without spiders. Once we collected two inflorescences from each $P$. rigida individual, the nested ANOVA with type III sum of squares was chosen for comparisons, since the inflorescence factor was nested within individual factor, which, in turn, was nested within morph factor or spider presence/absence factor. We considered inflorescence as individual random factors, whereas the morph or the spider presence/absence we considered as fixed factors. In order to compare the amount of fruits, intact and aborted flowers between inflorescence with and without spiders, we performed paired $t$-tests for each morph. We also tested, by performing bilateral Mann-Whitney $U$ tests, whether the amount of fruits and flowers differed between brevistylous and longistylous inflorescences, with spiders and without spiders. We compared the architectural heterogeneity between brevistylous and longistylous inflorescences through the principal component analysis (PCA) of correlation with a centered matrix, once the data set included eight architectural variables. The PCA matrix was set up by putting each sampled inflorescence as objects and architectural variables as the object attributes. By performing PCA, we could visualize general architectural patterns for both morphs as well as how the different architectural variables covariate with each other, allowing us to detect what architectural variables are most likely responsible for the differentiation between brevistylous and longistylous morphs. We used the software Statistica 7.0 (StatSoft) to perform the Mann-Whitney $U$-Test, $\chi^{2}$ test, nested ANOVA, and paired $t$-test, whereas for multivariate analysis of PCA and for estimation of species number by Coleman rarefaction, we used the softwares FITOPAC 2.1.2.85 [23] and EstimateS 7.5.0 [24], respectively. For the nested ANOVA and paired $t$-test, we transformed the response variable data set into $\log (n+1)$ in order to normalize and equalize the variances for parametric tests. We assumed the level of statistical significance as $P<0.05$ for all analyses performed.

\section{Results}

3.1. Spider Occurrence and Richness. Among the inflorescences with spiders on them, just about one or two spiders were collected per inflorescence. So, the spider richness on $P$. rigida inflorescence was a measure close to the spider abundance. Although the abundance of spiders per inflorescence was low, the spider presence/absence was still remarkably discrepant between the two floral morphs. The proportion of shrubs with adult spiders differed between 
TABLE 1: Frequency of spider morphospecies sampled on longistylous and brevistylous inflorescences of $P$. rigida.

\begin{tabular}{lcc}
\hline $\begin{array}{l}\text { Spider species and } \\
\text { morphospecies }\end{array}$ & $\begin{array}{c}\text { Frequency on } \\
\text { longistylous } \\
\text { inflorescences (\%) }\end{array}$ & $\begin{array}{c}\text { Frequency on } \\
\text { inflorescences }(\%)\end{array}$ \\
\hline
\end{tabular}

\begin{tabular}{lcc} 
Oxyopidae & \\
$\quad$ Oxyopes salticus Hentz, & 23.81 & - \\
1845 & & - \\
Thomisidae & 19.04 & - \\
$\quad$ Misumenops sp.1 & 9.52 & - \\
$\quad \begin{array}{l}\text { Deltoclita sp.1 } \\
\text { Deltoclita sp.2 }\end{array}$ & 4.77 & 13.3 \\
Salticidae & & \\
$\quad$ Corythalia sp.1 & 38.09 & - \\
Araneidae & & 2 \\
$\quad$ Araneus sp.1 & 4.77 & \\
\hline Total & 21 & \\
\hline
\end{tabular}

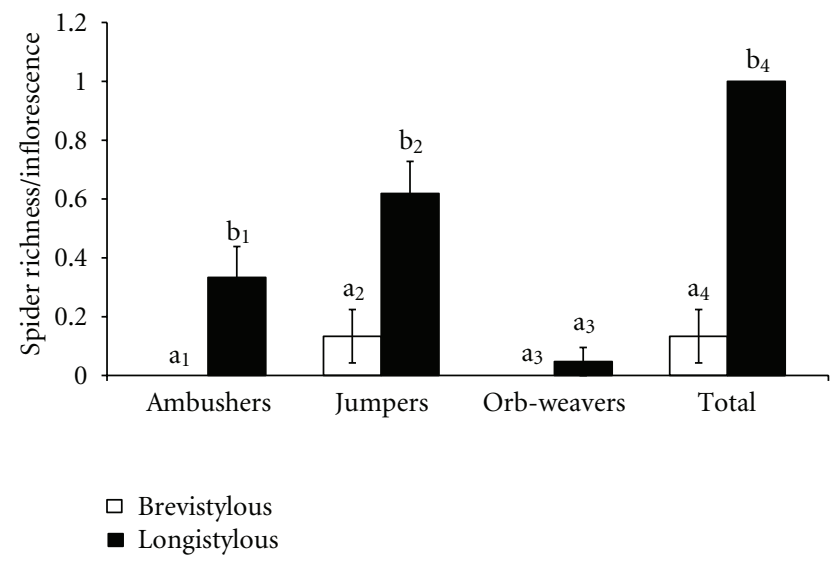

FIGURE 2: Spider guild richness per inflorescence in brevistylous and longistylous shrubs of $P$. rigida. Error bars represent \pm SE. The unequal letters above error bars indicate statistically significant differences at significance level of 0.05 .

brevistylous and longistylous morphs $\left(\chi^{2}=28.49, \mathrm{df}=\right.$ $1, P<0.0001$ ), since 2 out of 15 brevistylous shrubs sampled featured spiders on their inflorescences, whereas all the longistylous ones had spiders. We have found a total of six different spider species belonging to four families on $P$. rigida inflorescences (Table 1). Cursorial spider guilds were predominant on P. rigida inflorescences, since Corythalia sp.1 (Salticidae) was the most frequent species (38.09\%), followed by Oxyopes salticus Hentz, 1845 (Oxyopidae) (23.81\%), and Misumenops sp.1 (Thomisidae) (19.4\%) (Table 1). Only Corythalia had often been found inside silk structures, which were frequently built on inflorescence extremities and used as retreats. The retreat of each spider individual occupied about one third of the inflorescence length.

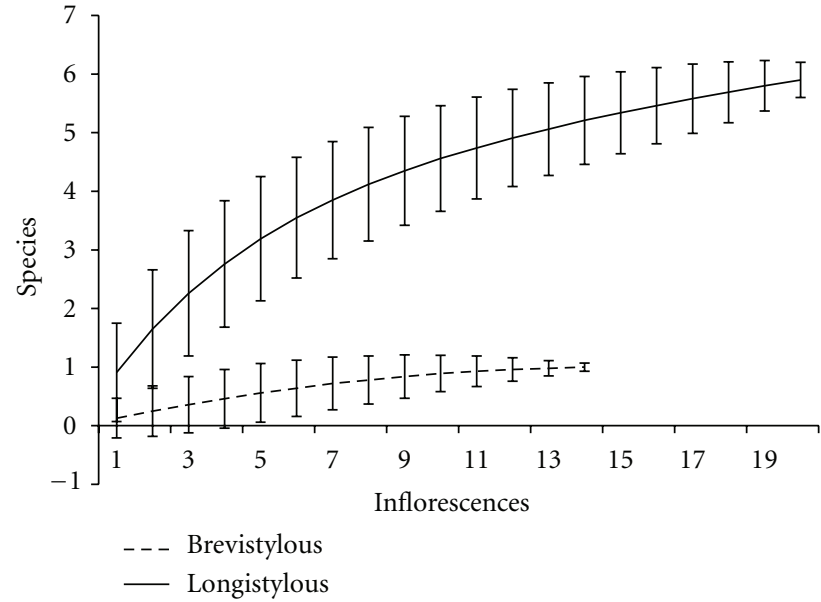

Figure 3: Coleman rarefaction curve for samples of brevistylous and longistylous inflorescences. Each inflorescence sample represents one distinct individual of $P$. rigida. Error bars across the two curves represent $\pm \mathrm{SD}$.

Total spider richness per inflorescence was higher among longistylous shrubs than among brevistylous ones (MannWhitney $U$-test; $z=-5.263, P<0.001$ ) (Figure 2). The same happened to the spiders of the guilds of Ambushers (Mann-Whitney $U$-test; $z=-2.456, P=0.014$ ) and Jumpers (Mann-Whitney $U$-test; $z=-2.873, P=0.004$ ) (Figure 2). However, the richness per inflorescence of the Orb-weavers guild did not differ between brevistylous and longistylous morphs (Mann-Whitney $U$-test; $z=-0.845$, $P=0.398)$. The estimated total number of spider species by the Coleman rarefaction method was higher for longistylous inflorescences, since the estimate was about five up to six species for longistylous and only one species for brevistylous (Figure 3). Thus, although each $P$. rigida inflorescence with spider on it presented just about one spider species, all the longistylous inflorescences sampled sheltered about five more spiders than the brevistylous ones.

3.2. Architectural Heterogeneity. The PCA performed for the architectural variables of inflorescences explained about $60 \%$ of all proved successful [25] (Table 2). On the plane formed by the first two PCA axes, we can observe the general tendency of longistylous inflorescences being architecturally more complex than brevistylous ones (Figures 1 and 4). Longistylous inflorescences tend to have higher density of different floral structures, such as closed or open buds, aborted flowers, and infrutescences. The density of higher order branches (such as secondary, tertiary, quaternary, and quinary branching) appears to be positively correlated to each other and more abundant among longistylous inflorescences. Although there is overlapping regarding architecture features between the two morphs, which is expected since the morphs belong to the same plant species, longistylous inflorescences seem to reach more extreme values among most architectural traits, which was responsible for much of the variance embraced in the first PCA axis (Figure 4). 


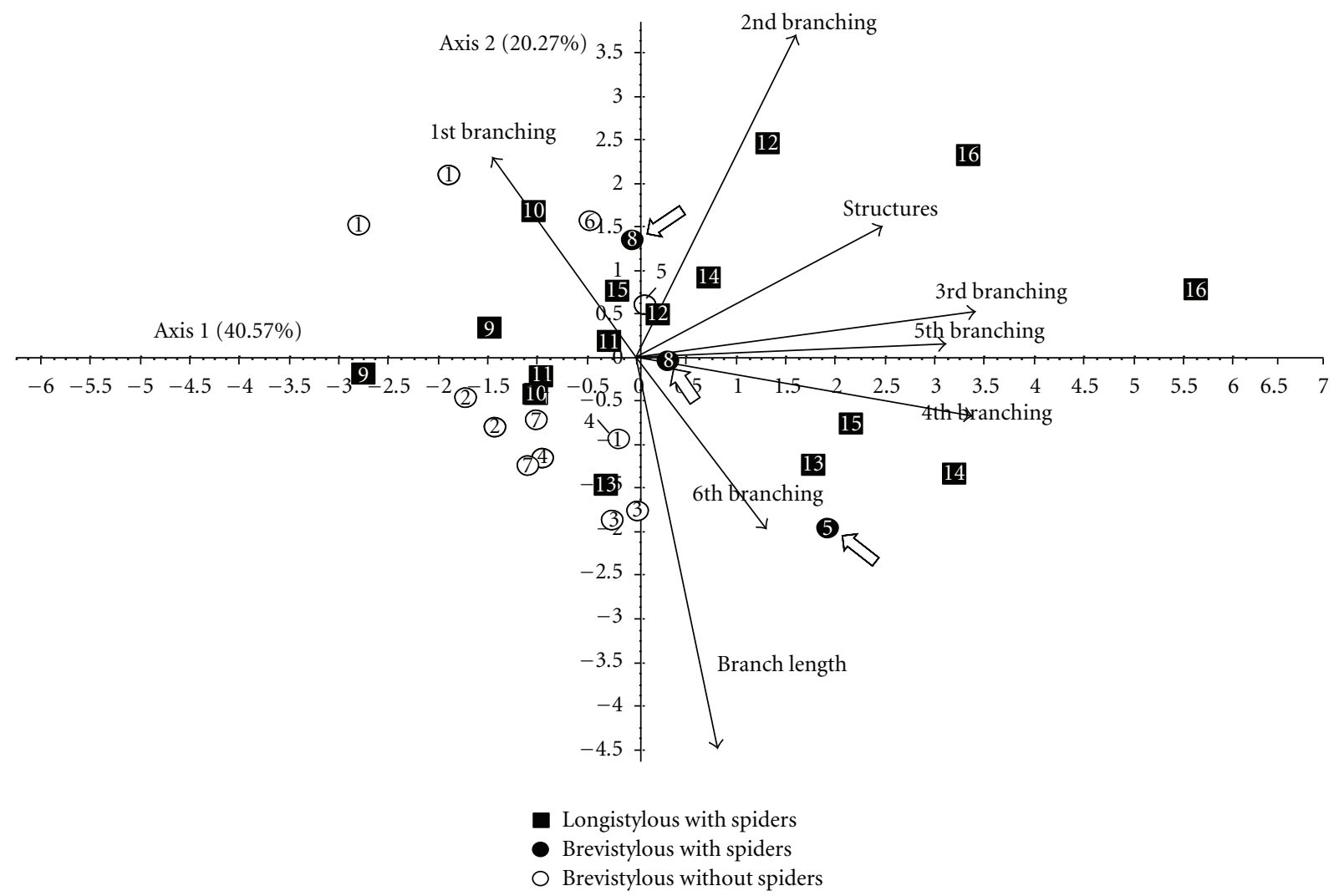

FIguRE 4: Graphic representation for the first two axes of the PCA performed with the architectural variables of $P$. rigida inflorescences. Objects: sampled brevistylous and longistylous inflorescences, the object number indicates the number of the sampled $P$. rigida shrub. Vectors and Structures: number of floral structures such as open and closed buds, floral abortions, and infrutescences; branch length: total inflorescence length; 1st, 2nd, 3rd, 4th, 5th, and 6th branching: density of primary, secondary, tertiary, quaternary, quinary, and senary branches, respectively.

The pattern of spider presence/absence on inflorescences also seems to follow the pattern of architectural complexity, since spiders tend to occur on architecturally more complex inflorescences. It is also noteworthy that the few brevistylous inflorescences with associated spiders present architectural features relatively more complex than the other brevistylous, such as greater density of secondary and senary branches (Figure 4, block arrows).

3.3. Sugar Concentration and Nectar Volume Produced. There was no difference neither in nectar volume $\left(F_{1,74}=0.243\right.$, $P=0.633)$ nor sugar concentration $\left(F_{1,74}=0.855\right.$, $P=0.378$ ) between the two morphs (Figure 5). There was also no difference between inflorescences with and without spiders regarding to nectar volume $\left(F_{1,74}=0.538, P=\right.$ $0.48)$ or sugar concentration $\left(F_{1,74}=0.35, P=0.566\right.$ (Figure 5). Indeed, nectar volume and sugar concentration varied significantly from individual to individual, regardless of which morph it belonged to (nectar volume: $F_{9,74}=4.828$, $P=0.008$; sugar concentration: $\left.F_{9,74}=14.8, P<0.0001\right)$ or of the spider presence (nectar volume: $F_{9,74}=7.721$, $P=0.001$; sugar concentration: $F_{9,74}=4.045, P=0.014$ ). So, we do not have evidence for difference in nectar volume
TABLE 2: Eigenvalues, cumulative percent variation, and eigenvectors of the first three principal components axes for the eight architecture variables of longistylous and brevistylous $P$. rigida inflorescences.

\begin{tabular}{lccc}
\hline & Axis 1 & Axis 2 & Axis 3 \\
\hline Eigenvalue & 3.246 & 1.622 & 0.883 \\
Percent variation & 40.57 & 20.27 & 11.04 \\
$\begin{array}{l}\text { Percent variation as expected } \\
\text { by the broken stick model }\end{array}$ & 33.97 & 21.47 & 15.22 \\
Eigenvectors & & & \\
$\quad$ 1st branching & -0.2123 & 0.3369 & -0.4324 \\
2nd branching & 0.2382 & 0.5445 & 0.2173 \\
3rd branching & 0.5034 & 0.0770 & 0.0039 \\
4th branching & 0.4984 & -0.1012 & -0.1052 \\
5th branching & 0.4591 & 0.0212 & -0.4433 \\
6th branching & 0.1925 & -0.2925 & 0.6737 \\
Branch length & 0.1218 & -0.6626 & -0.3186 \\
Structures & 0.3658 & 0.2208 & 0.0536 \\
\hline
\end{tabular}

or sugar concentration between the two morphs or between inflorescences with and without spiders. 

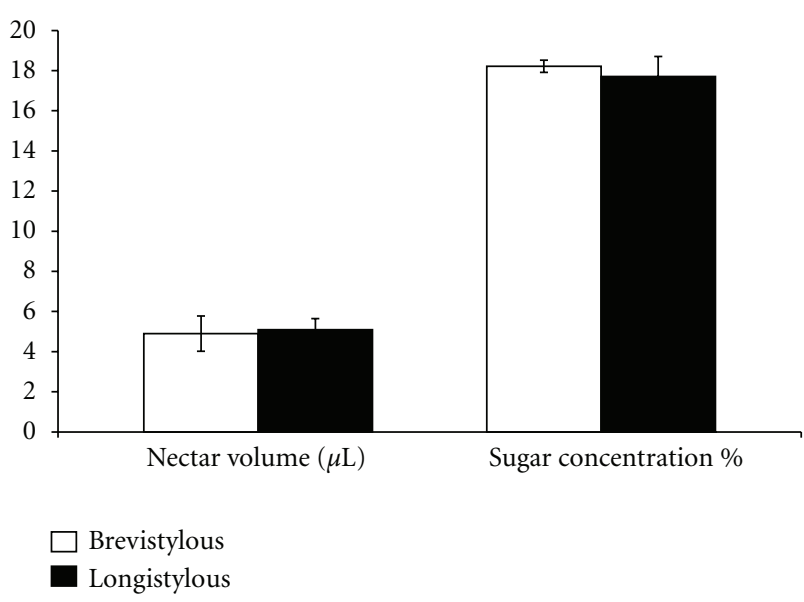

(a)

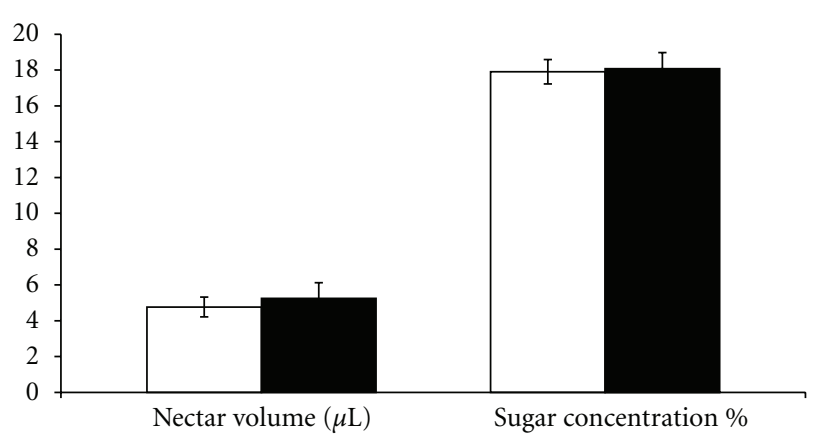

$\square$ With spiders

Without spiders

(b)

FIGURE 5: Nectar volume and sugar concentration between (a) brevistylous and longistylous morphs and between inflorescences (b) with and without spiders. Error bars represent \pm SE.

3.4. Abundance of Fruits and Flowers. The differences in the amount of fruits, intact flowers, and aborted flowers between inflorescences with and without spiders were not significant for both brevistylous (paired $t$-test fruits: $t=0.241$, $\mathrm{df}=4$, $P=0.821$; intact flowers: $t=-1.362$, df $=4, P=0.245$; aborted flowers: $t=-2.234$, df $=4, P=0.089)$ and longistylous morph (paired $t$-test fruits: $t=1.685, \mathrm{df}=12$, $P=0.118$; intact flowers: $t=-0.054$, df $=12, P=$ 0.958; aborted flowers: $t=0.343$, df $=12, P=0.737$ ) (Figure 6). There was also no difference in the amount of fruits and flowers (intact or aborted) between brevistylous and longistylous inflorescences with spiders (Mann-Whitney $U$-test fruits: $z=1.178, P=0.239$; intact flowers: $z=1.004$, $P=0.315$; aborted flowers: $z=0.829, P=0.407)$ and without spiders (Mann-Whitney $U$-test fruits: $z=0.000$, $P=1.000$; intact flowers: $z=1.626, P=0.104$; aborted flowers: $z=1.128, P=0.200)$. Therefore, we did not find any evidence for a relationship between the inflorescence morph or the spider occurrence and the abundance of fruits and flowers (intact or aborted) in P. rigida inflorescences.

\section{Discussion}

The spider occurrence pattern was remarkably distinct between the two morphs, with most of the spiders occurring on the longistylous morph. The total spider richness was also higher on longistylous inflorescences than on brevistylous ones. Thus, the evidence supports the view that there is some sort of difference in habitat quality between these two morphs. However, the two morphs differed more consistently only with respect to architectural heterogeneity, since longistylous inflorescence is, on average, architecturally more complex than brevistylous. Therefore, this study presents some evidence in favor of the structural heterogeneity hypothesis $[26,27]$ regarding the spider occurrence pattern on related inflorescences. The habitat architecture actually is often related to the availability of refuge for protection against predators and abiotic adversities, such as physical disturbance and harsh climatic conditions [13]. The higher refuge availability against intraguild predation can result in a higher predator richness and abundance in architecturally complex environments [28, 29]. Furthermore, complex architecture provides more attaching points for spider silk structures, such as snare webs and retreats $[4,15]$. So, the higher spider occurrence and total richness on longistylous inflorescences may then be explained, at least partially, by their greater architectural complexity due to increasing shelter availability and suitability for building silk structures.

We have no evidence that other characteristics related to habitat quality in $P$. rigida inflorescences, such as nectar volume, sugar concentration, and quantity of flowers and fruits, are in some way correlated to the presence of spiders. Such characteristics are usually related to the prey abundance on inflorescences, since they are largely responsible for attracting pollinators and phytophagous [3032]. However, we should note that P. rigida, like many other of Rubiaceae family [33], is an ornithophilous species that is primarily pollinated by hummingbirds, with insects such as bees, moths, and flies only occurring as occasional visitors [21]. For example, [14] compared inflorescences of an ornithophilous species (Palicourea guianensis, Rubiaceae) with a species pollinated by bees and butterflies (Lantana camara, Verbenaceae) and found that the ornithophilous one had much lower density of insects and spiders than the one pollinated by insects. Since insect pollinators represent an important prey source for spiders on inflorescences [34, 35], it is possible that, for ornithophilous species such as $P$. rigida, prey availability would not be a main factor influencing foraging substrate choice by spiders on inflorescences, rather other factors would be more important such as refuge availability provided by the complex architecture of reproductive branches. In [6], for example, even artificial inflorescences, which were very poor in prey, attracted more spiders than vegetative branches, indicating that spiders can select habitat based only on architecture per se. Taking into consideration the significant importance of tactile signals for the environment perception by spiders $[1,35]$, it is possible that the architectural configuration of plant structures is one of the main cues used by spiders in selection of foraging substrates. 


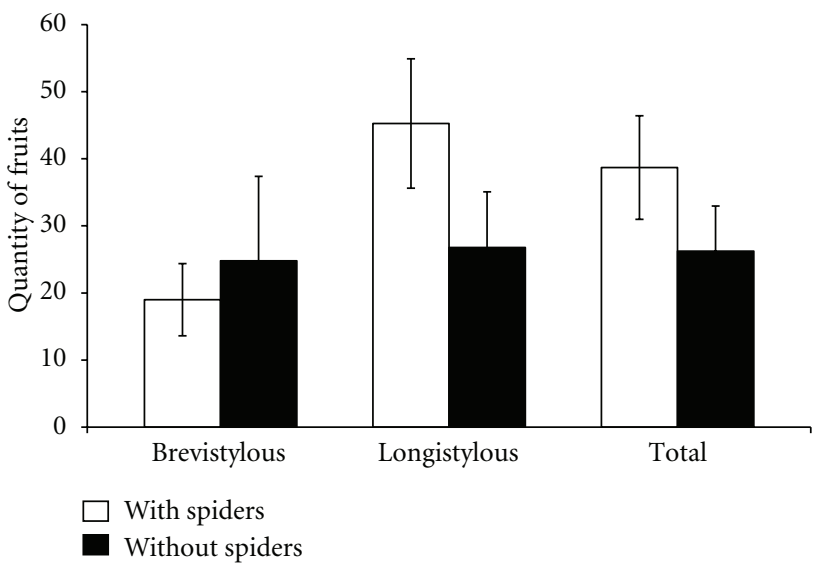

(a)

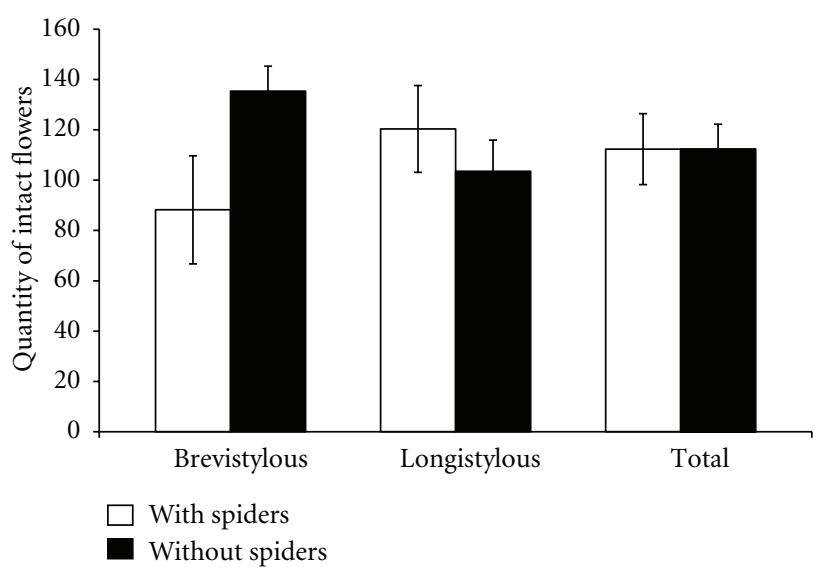

(b)

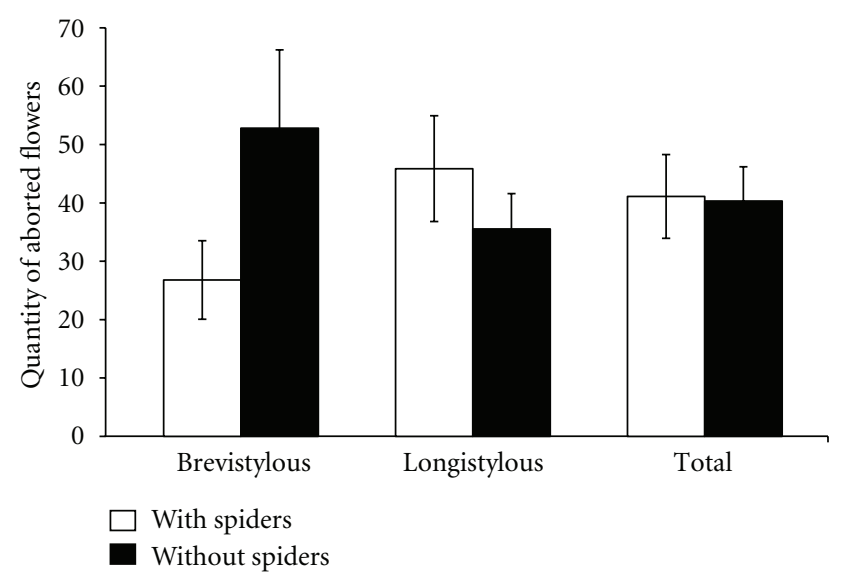

(c)

FIGURE 6: Quantity of fruits (a) and of intact (b) and aborted flowers (c) on brevistylous and longistylous inflorescences with and without spiders. Error bars represent $\pm \mathrm{SE}$.

Another important aspect is the presence of nectaries at the corolla base of the plant, which could attract other visitors to these resources, such as ants. The presence of ants culminates in the protection of the plant against herbivores action, reducing leaf area loss and increasing fruit set production [36]. Thus, multiple predators (ants and spiders) often have effects on their common prey populations that cannot be predicted by summing the effects of each predator at a time. Recently, [5] experimentally evaluated the effects of spiders and ants on herbivory and reproduction of Q. multiflora by dividing the trees in four experimental groups, depending on the presence or absence of ants and spiders. Results showed that the presence of ants reduced the abundance and richness of spiders, but spiders did not affect the abundance and richness of ants. Only the removal of ants resulted in a statistically significant increase in the herbivore abundance and richness. Herbivory, however, was also affected by spiders. In addition, authors found a significant interaction effect of ants and spiders on herbivory, indicating an emergent multiple predator effect. This study highlights the importance of evaluating the effect of the predator fauna as a whole and not only one specific group on herbivory. Moreover, the presence of ants on $P$. rigida as well as its ornithophilous pollination, as discussed before, is likely the cause, at least partially, of the low spider species richness and abundance on $P$. rigida inflorescences. Also, once spiders are usually solitary and aggressive toward both heterospecific and conspecific spiders [37] and the fact that many spider retreats occupied about one third of $P$. rigida inflorescence length, it would be possible that the paucity of spiders on $P$. rigida inflorescences is partly due to the lack of proximity tolerance among spiders. The presence of spiders on inflorescences may easily affect the plant reproductive success. Spiders can prey on phytophagous harmful to the floral structures and consequently reduce their abundance, a fact that lead to an increase in plant reproductive success [3]. Indeed, several studies have demonstrated that spiders may play an effective role in biological pest control $[2,38]$. Although intra-guild predation and generalist spider habits could dilute their impact on phytophagous, the presence of a rich araneofauna and refuge availability may reduce the dilution effect, leading to the control and stability of prey populations by the spider assemblage $[2,28,39]$. Speculatively, it would be 
possible that longistylous inflorescences, due to the higher spider occurrence and architectural complexity, suffer less damage from phytophagous in their floral structures than brevistylous ones. The fact that cursorial guilds, such as ambushers and jumpers, are present mostly on longistylous inflorescences than on brevistylous ones also supports this conjecture, since cursorial spiders are the main predators in multispecies arthropod interactions [3] and probably the main agents of biological control [2]. Also, although there was a low spider number per longistylous inflorescence, synergic effects with other predators like ants might enhance the effect of spider presence on floral phytophagous. Albeit in this study we had not presented differences in number of fruits or intact and aborted flowers between the two $P$. rigida morphs, it would be possible that the effects of spider presence on longistylous inflorescences become evident on other $P$. rigida reproductive factors, such as seed viability and successful establishment of seedlings. Thus, it should be interesting for a future study to compare the viability of seeds and seedlings between the two morphs.

The fact that two floral morphs of the same plant species present a spider occurrence so distinct from each other is a really intriguing fact and worth further investigation. Moreover, the fact that the spiders are still present on almost all the longistylous inflorescences despite the unfavorable conditions for their establishment on $P$. rigida, such as the presence of ants and the ornithophilous pollination, reinforces the idea that longistylous inflorescences have some traits that enhance the habitat suitability for spiders. If plant architecture is the main factor for the spider presence differentiation between the two morphs, we might say that architectural modifications in inflorescences may alter the occurrence pattern of at least some predator groups. Thus, plant architecture variations could lead to bottom-up effects and influence the phytophagous abundance through modifications on predator occurrence pattern. Hence, would it be possible that a distinct architecture between two floral morphs may yield differential reproductive success due to variations on the phytophagous damage magnitude? Experimental studies with $P$. rigida and other heterostylous plant species, preferentially with higher spider abundance on their inflorescences, would eventually answer this question.

\section{Disclosure}

Three statistical packages were utilized for the data analysis. The authours chose Statistica 7.0 in order to perform nonparametric tests and Analysis of Variance, whereas for the Principal Component Analysis, they preferred Fitopac 2.1.2.85, since this statistical package is specific for Multivariate Analysis. The EstimateS 7.50 software is specific for species richness estimation, which is not performed either by Statistica or Fitopac packages. So, the software choice was solely based on the suitability of analysis properties from each statistical package in order to accomplish the research objectives.

\section{Acknowledgments}

The authors thank the Graduate Program in Ecology and Conservation of Natural Resources of Universidade Federal de Uberlândia and also the directors and employees of Parque Estadual de Caldas Novas (PESCAN), for the possibility of collecting in the park. They also wish to recognize the Coordenação de Aperfeiçoamento de Pessoal de Nível Superior- Plano Nacional de Pós-Doutorado (CAPES-PNPD 2556/2011) (V. Stefani) D. Lange: AT/500868/20107) for financial support.

\section{References}

[1] R. F. Foelix, Biology of Spiders, Oxford University Press, Oxford, UK, 1996.

[2] G. Q. Romero, "Aranhas como agentes de controle biológico em agroecossistemas," in Ecologia e Comportamento de Aranhas, M. O. Gonzaga, A. Santos, and H. F. Japyassú, Eds., pp. 301-315, Editora Interciência, Rio de Janeiro, Brazil, 2007.

[3] G. Q. Romero, J. C. Souza, and J. Vasconcellos-Neto, "Antiherbivore protection by mutualistic spiders and the role of plant glandular trichomes," Ecology, vol. 89, no. 11, pp. 31053115, 2008.

[4] J. Halaj, D. W. Ross, and A. R. Moldenke, "Importance of habitat structure to the arthropod food-web in Douglas-fir canopies," Oikos, vol. 90, no. 1, pp. 139-152, 2000.

[5] L. Nahas, M. O. Gonzaga, and K. Del-Claro, "Emergent Impacts of ant and spiders interactions: herbivory reduction in a tropical savanna tree," Biotropica, vol. 44, no. 4, pp. 498$505,2012$.

[6] A. L. Teixeira De Souza and R. P. Martins, "Distribution of plant-dwelling spiders: inflorescences versus vegetative branches," Austral Ecology, vol. 29, no. 3, pp. 342-349, 2004.

[7] A. L. T. Souza and R. P. Martins, "Foliage density of branches and distribution of plant-dwelling spiders," Biotropica, vol. 37, no. 3, pp. 416-420, 2005.

[8] C. L. Hatley and J. A. Macmahon, "Spider community organization: seasonal variation and the role of vegetation architecture," Environmental Entomology, vol. 9, pp. 632-639, 1980.

[9] T. A. Evans, "Distribution of social crab spiders in eucalypt forests," Austral Ecology, vol. 22, no. 1, pp. 107-111, 1997.

[10] R. A. Balfour and A. L. Rypstra, "The influence of habitat structure on spider density in a no-till soybean agroecosystem," Journal of Arachnology, vol. 26, no. 2, pp. 221-226, 1998.

[11] J. Raizer and M. E. C. Amaral, "Does the structural complexity of aquatic macrophytes explain the diversity of associated spider assemblages?" Journal of Arachnology, vol. 29, no. 2, pp. 227-237, 2001.

[12] M. Scheidler, "Influence of habitat structure and vegetation architecture on spiders," Zoologischer Anzeiger, vol. 225, no. 56, pp. 333-340, 1990.

[13] R. F. Denno, D. L. Finke, and G. A. Langellotto, "Direct and indirect effects of vegetation structure and habitat complexity on predator-prey and predator-predator interactions," in Ecology of Predator-Prey Interactions, P. Barbosa and I. Castellanos, Eds., pp. 211-239, Oxford University Press, Oxford, UK, 2005.

[14] W. Nentwig, Spiders of Panama, Flora \& Fauna Handbook 12, Sandhill Crane Press, Gainesville, Fla, USA, 1993. 
[15] A. L. T. Souza, "Influência da estrutura do habitat na distribuição de aranhas," in Ecologia e Comportamento de Aranhas, M. O. Gonzaga, A. Santos, and H. F. Japyassú, Eds., pp. 25-43, Editora Interciência, Rio de Janeiro, Brazil, 2007.

[16] S. A. Chien and D. H. Morse, "The roles of prey and flower quality in the choice of hunting sites by adult male crab spiders Misumena vatia (Araneae, Thomisidae)," Journal of Arachnology, vol. 26, no. 2, pp. 238-243, 1998.

[17] J. Carlos-Santos and K. Del-claro, "Interações entre formigas, herbívoros e nectários extraflorais em Tocoyena formosa (Rubiaceae) em vegetação de cerrado," Revista Brasileira de Zoociências, vol. 3, no. 1, pp. 77-92, 2001.

[18] A. F. Almeida and F. N. M. Sarmento, Parque Estadual da Serra de Caldas-Plano de Manejo. CTE, (Centro Tecnológico de Engenharia Ltda), FEMAGO—Fundação Estadual do Meio Ambiente, Goiânia, Brazil, 1998.

[19] J. F. Ribeiro and B. M. T. Walter, "Fitofisionomias do bioma Cerrado," in Cerrado: Ambiente e Flora, S. M. Sano and S. P. Almeida, Eds., pp. 89-166, EMBRAPA. Planaltina, 1998.

[20] J. A. Ratter, S. Bridgewater, and J. F. Ribeiro, "Analysis of the floristic composition of the Brazilian cerrado vegetation III: comparison of the woody vegetation of 376 areas," Edinburgh Journal of Botany, vol. 60, no. 1, pp. 57-109, 2003.

[21] A. O. Machado, Cões florais e heterostilia em Palicourea rigida (rubiaceae) nos Cerrados do Brasil central (Master of Science Dissertation) Universidade Federal de Uberlândia, Uberlândia, Brazil, 2007.

[22] A. P. Silva, Biologia reprodutiva e polinização de Palicourea rigida H.B.K. (Rubiaceae), (Master of Science Dissertation), Universidade de Brasília, Brasília, Brazil, 1995.

[23] G. J. Shepherd, Fitopac 2.1.2.85. Manual do Usuário, Departamento de Botânica, Universidade Estadual de Campinas, Campinas, Brazil, 2010.

[24] R. K. Colwell, EstimateS: Statistical estimation of species richness and shared species from samples (Software and User's Guide, Version 7.5, 2005, http://viceroy.eeb.uconn.edu/ estimates/.

[25] R. H. MacArthur, "On the relative abundance of bird species," Proceedings of the National Academy of Sciences of the USA, vol. 43, pp. 293-295, 1957.

[26] J. H. Lawton, "Plant architecture and the diversity of phytophagous insects," Annual Review of Entomology, vol. 28, pp. 23-39, 1983.

[27] E. D. Mccoy and S. S. Bell, "Habitat structure: the evolution and diversifications of a complex topic," in Habitat Structure: The Physical Arrangement of Objects in Space, S. S. Bell, E. D. McCoy, and R. H. Mushinsky, Eds., pp. 3-27, Chapman \& Hall, London, UK, 1991.

[28] D. L. Finke and R. F. Denno, "Intraguild predation diminished in complex-structured vegetation: implications for prey suppression," Ecology, vol. 83, no. 3, pp. 643-652, 2002.

[29] D. L. Finke and R. F. Denno, "Spatial refuge from intraguild predation: implications for prey suppression and trophic cascades," Oecologia, vol. 149, no. 2, pp. 265-275, 2006.

[30] C. M. Hodges, "Optimal foraging in bumblebees: hunting by expectation,” Animal Behaviour, vol. 29, no. 4, pp. 1166-1171, 1981.

[31] L. S. Best and P. Bierzychudek, "Pollinator foraging on foxglove (Digitalis purpurea): a test of a new model," Evolution, vol. 36, pp. 70-79, 1982.

[32] G. Dalby-Ball and A. Meats, "Effects of fruit abundance within a tree canopy on the behaviour of wild and cultured
Queensland fruit flies, Bactrocera tryoni (Froggatt) (Diptera: Tephritidae)," The Australian Journal of Entomology, vol. 39, no. 3, pp. 201-207, 2000.

[33] L. B. Mendonça and L. Dos Anjos, "Flower morphology, nectar features, and hummingbird visitation to Palicourea crocea (Rubiaceae) in the Upper Paraná River floodplain, Brazil," Anais da Academia Brasileira de Ciencias, vol. 78, no. 1, pp. 45-57, 2006.

[34] S. M. Louda, "Inflorescence spiders: a cost/benefit analysis for the host plant, Haplopappus venetus Blake (Asteraceae)," Oecologia, vol. 55, no. 2, pp. 185-191, 1982.

[35] D. H. Morse, Predator upon a Flower, Life History and Fitness in a Crab Spider, Harvard University Press, London, UK, 2007.

[36] K. Del-Claro, V. Berto, and W. Réu, "Effect of herbivore deterrence by ants on the fruit set of an extrafloral nectary plant, Qualea multiflora (Vochysiaceae)," Journal of Tropical Ecology, vol. 12, no. 6, pp. 887-892, 1996.

[37] D. H. Wise, Spiders in Ecological Webs, Cambridge University Press, Cambridge, UK, 1993.

[38] R. G. Breene, D. A. Dean, M. Nyffeler, and G. B. Edwards, Biology, Predation Ecology, and Significance of Spiders in Texas Cotton Ecosystems with a Key to the Species, Texas Agricultural Experiment Station, Texas,Tex, USA, 1993.

[39] S. E. Riechert and T. Lockley, "Spiders as biological control agents," Annual Review of Entomology, vol. 29, pp. 299-320, 1984. 

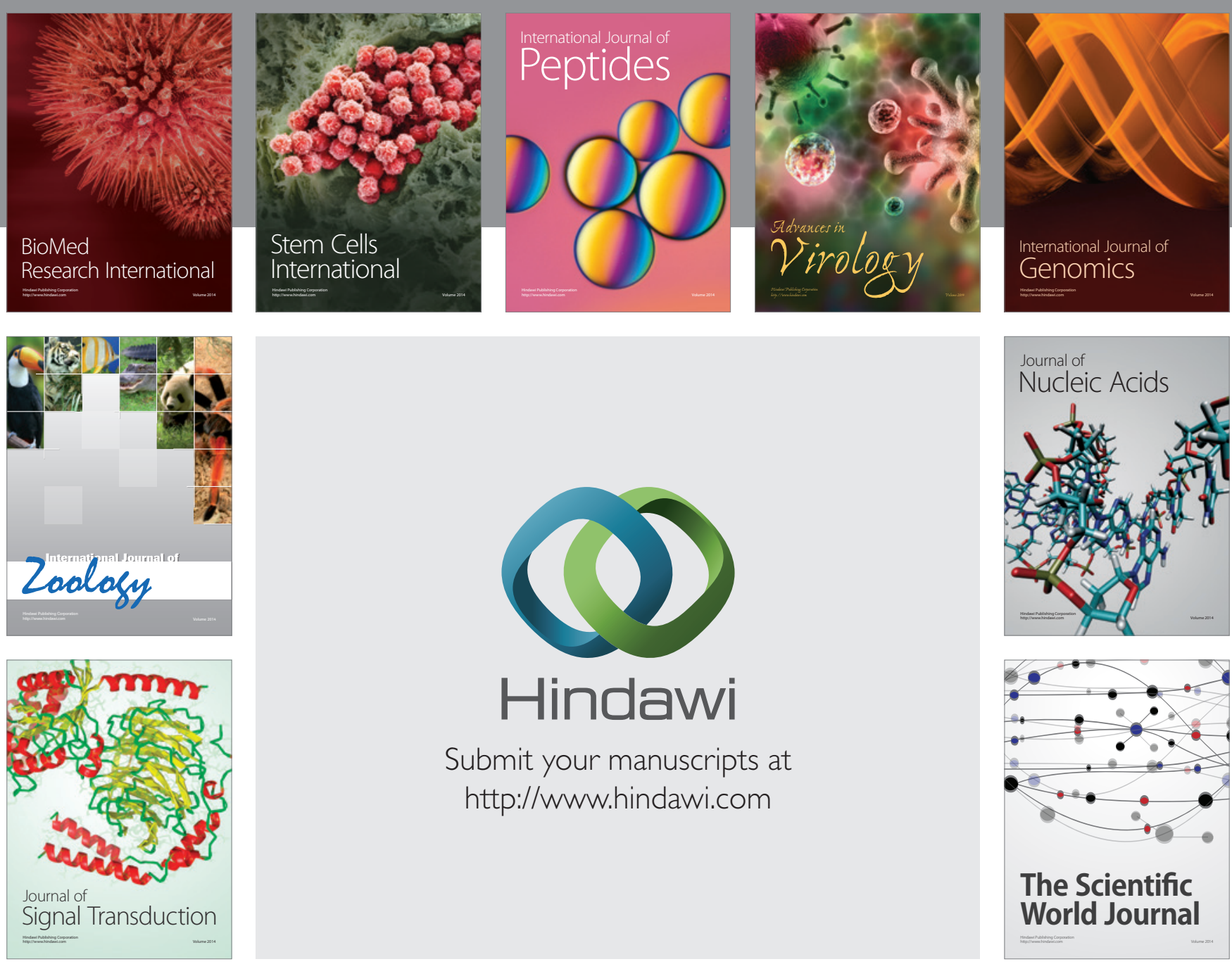

Submit your manuscripts at

http://www.hindawi.com
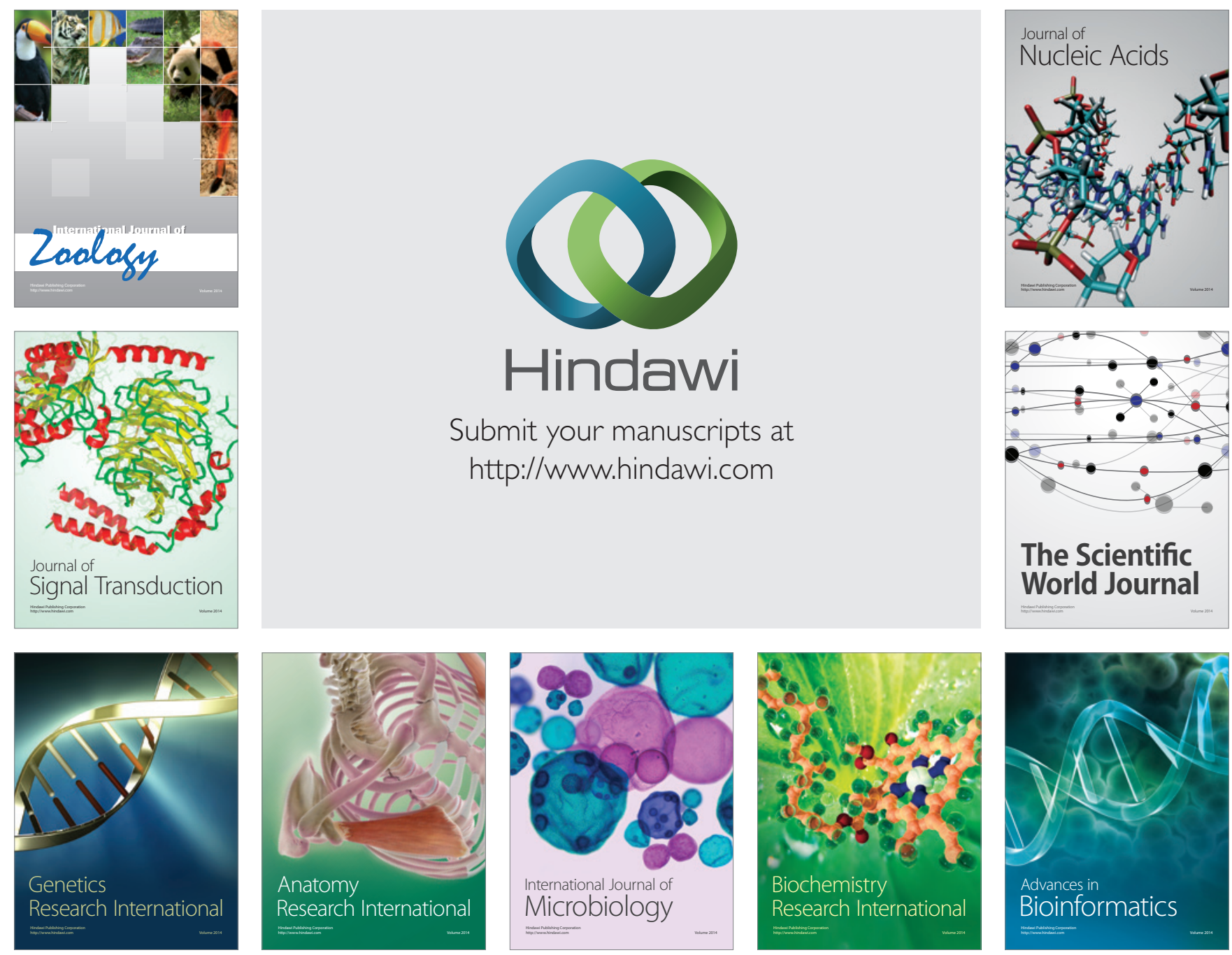

The Scientific World Journal
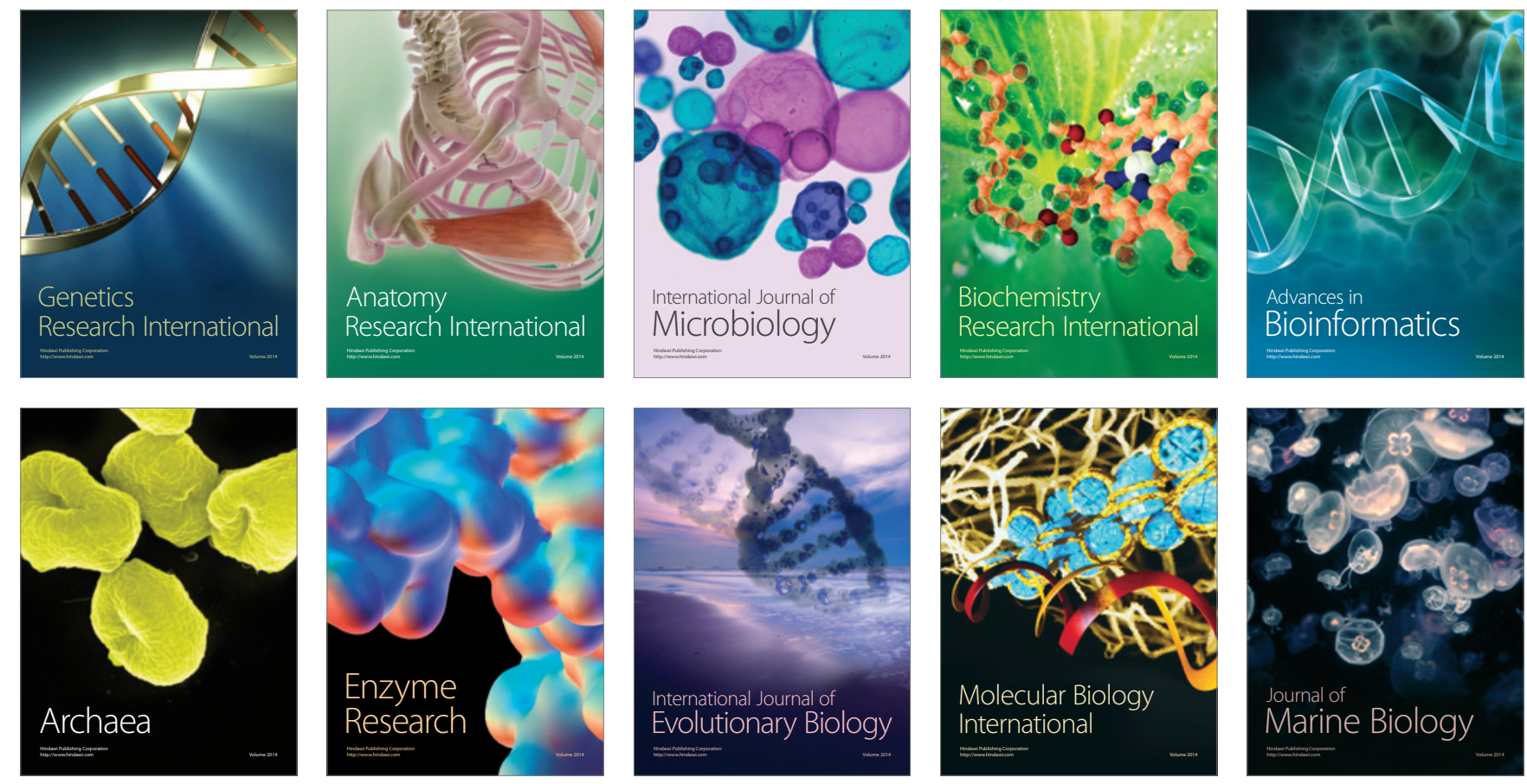